Check for updates

Cite this: Chem. Sci., 2019, 10, 8399

๑ All publication charges for this article have been paid for by the Royal Society of Chemistry

Received 18th May 2019

Accepted 24th July 2019

DOI: $10.1039 /$ c9sc02448d

rsc.li/chemical-science

\section{Light-induced metal-free transformations of unactivated pyridotriazoles $\uparrow$}

\author{
Ziyan Zhang,,$^{\mathrm{ab}}$ Dongari Yadagirit ${ }^{\mathrm{ab}}$ and Vladimir Gevorgyan (D) *ab
}

A highly efficient and practical method for incorporation of the arylmethylpyridyl moiety into diverse molecules has been developed. This method features the transition metal-free light-induced room temperature transformation of pyridotriazoles into pyridyl carbenes, which are capable of smooth arylation, $\mathrm{X}-\mathrm{H}$ insertion, and cyclopropanation reactions. The synthetic usefulness of the developed method was illustrated in a facile synthesis of biologically active molecules.
Transition metal-catalyzed denitrogenative transformations of pyridotriazoles have been recently evolving as a powerful tool for synthesis of diverse molecules possessing N-hetero-cyclic fragments. ${ }^{1,2}$ These protocols take advantage of the wellknown ring-chain tautomerism of the pyridotriazole core in solution into the corresponding diazo tautomer $\mathbf{A}$, which then can be trapped by a transition metal catalyst to form the reactive pyridyl metal carbene intermediate $\mathbf{B}$ (Scheme 1a). Since the first report on the transannulation reaction of pyridotriazoles in $2007,{ }^{3}$ numerous effective catalytic methods including transannulation, ${ }^{4} \mathrm{X}-\mathrm{H}$ insertions, ${ }^{5}$ and cyclopropanation $^{6}$ reactions have been developed. ${ }^{7}$ However, all these methods are not without shortcomings. The reactions proceeding at room temperature require $\mathrm{Cl}, \mathrm{Br}$, or OMe activating groups $(\mathrm{AG})$ at $\mathrm{C} 7,,^{3 a, b}$ otherwise high temperatures $\mathrm{s}^{3 c-e}$ are necessary for achieving sufficient amounts of the open form of pyridotriazole A, which would lead to the reaction products. In either case, the employment of transition metal catalysts is required. Herein, we report room temperature efficient and operationally simple light-induced metal-free arylation, $\mathrm{X}-\mathrm{H}$ insertion, and cyclopropanation reactions of pyridotriazoles giving access to various pyridyl-containing synthons, which can be used for convenient synthesis of bioactive molecules.

In continuation of our studies on application of pyridotriazoles in the synthesis of nitrogen-containing heterocycles, ${ }^{3 a-e}$ we hypothesized a metal-free strategy which can be accessed by utilizing light irradiation. ${ }^{8}$ Compared with numerous methods reported for thermal processes,

aDepartment of Chemistry, University of Illinois at Chicago, 845 W. Taylor St., Chicago, Illinois, 60607, USA

${ }^{b}$ Department of Chemistry and Biochemistry, University of Texas at Dallas, $800 \mathrm{~W}$ Campbell RD, Richardson, Texas, 75080, USA. E-mail: vlad@utdallas.edu

$\dagger$ Electronic supplementary information (ESI) available. See DOI: $10.1039 / \mathrm{c} 9 \mathrm{sc} 02448 \mathrm{~d}$

$\ddagger$ These authors contributed equally to this work. photochemical studies of pyridiotriazoles are relatively scarce. ${ }^{9}$ Aiming at the development of milder reaction conditions, we started our investigation by analysing the UV-vis absorption spectra of pyridotriazoles 1a-d (Fig. 1, see ESI $\dagger$ for more details). Among them, only pyridotriazoles $\mathbf{1 a}$ and $\mathbf{1 b}$ bearing aryl substituents at the $\mathrm{C} 3$ position showed appreciable absorption around $390 \mathrm{~nm}$ region, which is attributed to the extended conjugation in these systems. Thus, we hypothesized that upon irradiation, the excited pyridotriazole 1a could undergo a ring-chain tautomerism to deliver its diazo tautomer

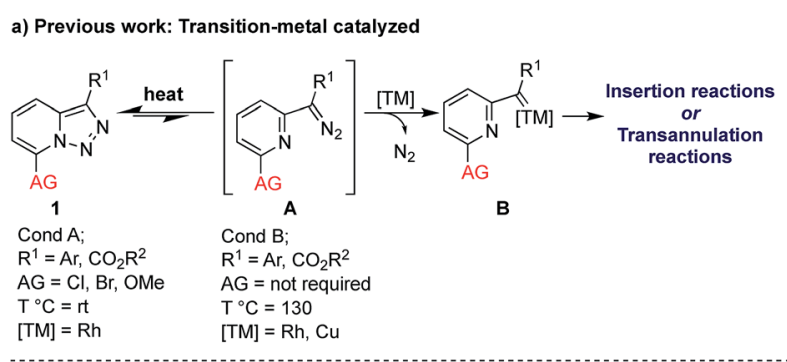

b) This work: Metal-free

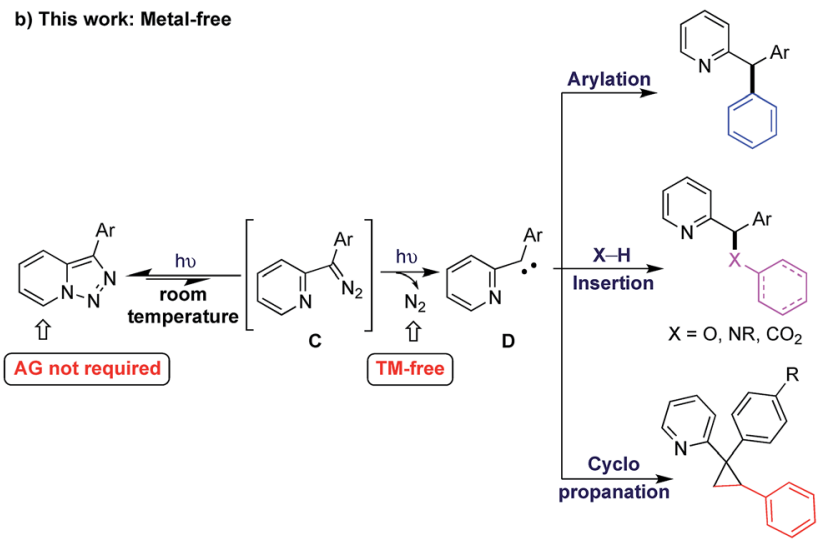

Scheme 1 Thermal and light-induced generation of carbenes from pyridotriazoles. 


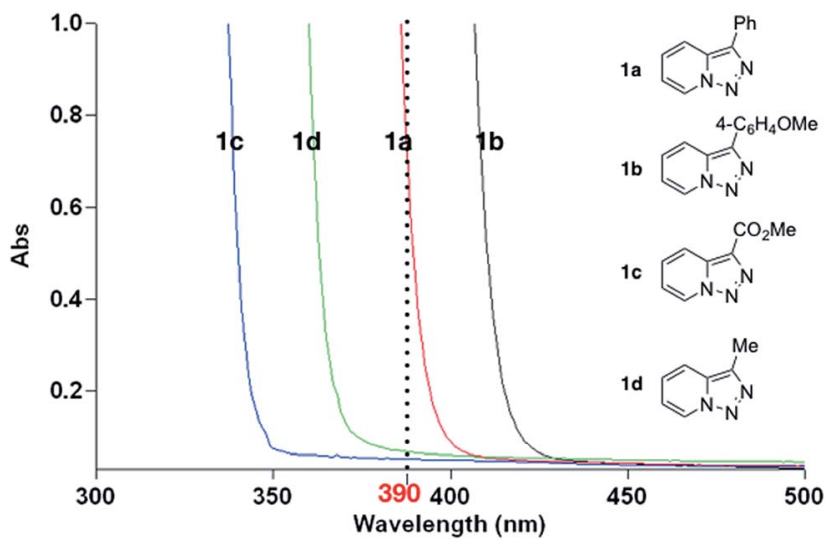

Fig. 1 UV-vis absorption spectra of pyridotriazoles.

C (Scheme 1b), which upon denitrogenation ${ }^{10}$ would deliver reactive carbene species $\mathbf{D}$.

To test this hypothesis, we examined a metal-free arylation reaction of 3 -phenyl[1,2,3]triazolo[1,5-a]pyridine 1a with boronic acid 2 (Table 1). The optimization studies indicated that performing this reaction under $390 \mathrm{~nm}$ irradiation in $0.1 \mathrm{M}$ benzene solution with 1.5 equiv. of boronic acid in the presence of 3 equiv. $\mathrm{K}_{2} \mathrm{CO}_{3}$ at room temperature allows to produce diphenyl-2-pyridylmethane 3aa in $89 \%$ yield (entry 1). Employment of other additives (entries 2-4) or solvents (entries 5-7) led to diminished yields. Only $25 \%$ of the product was formed without $\mathrm{K}_{2} \mathrm{CO}_{3}$ (entry 8), which points on the importance of the base for formation of the reactive triphenylboroxine arylating reagent. ${ }^{7 a}$ The control experiments indicated no reaction under $455 \mathrm{~nm}$ or $427 \mathrm{~nm}$ LED irradiating (entries 9 and 10) or under

Table 1 Optimization of arylation reaction parameters ${ }^{a}$<smiles></smiles><smiles>OBc1ccccc1</smiles>
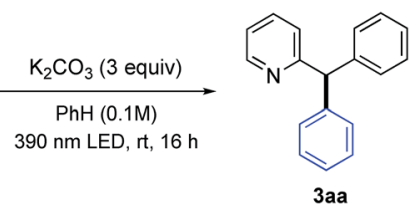

\begin{tabular}{lll}
\hline Entry & Deviation from standard conditions & Yield ${ }^{b}, \%$ \\
\hline 1 & None & 89 \\
2 & $\mathrm{Cs}_{2} \mathrm{CO}_{3}$ instead of $\mathrm{K}_{2} \mathrm{CO}_{3}$ & 73 \\
3 & $\mathrm{~K}_{3} \mathrm{PO}_{4}$ instead of $\mathrm{K}_{2} \mathrm{CO}_{3}$ & 44 \\
4 & $\mathrm{NEt}_{3}$ instead of $\mathrm{K}_{2} \mathrm{CO}_{3}$ & 40 \\
5 & $\mathrm{PhMe} \mathrm{instead} \mathrm{of} \mathrm{PhH}^{\mathrm{PhH}}$ & 84 \\
6 & $\mathrm{THF} \mathrm{instead} \mathrm{of} \mathrm{PhH}_{7}$ & 0 \\
7 & $\mathrm{CHCl}_{3}$ instead of $\mathrm{PhH}$ & 24 \\
8 & Without $\mathrm{K}_{2} \mathrm{CO}_{3}$ & 25 \\
9 & 455 nm LED instead of $390 \mathrm{~nm}$ LED & 0 \\
10 & 427 nm LED instead of $390 \mathrm{~nm} \mathrm{LED}$ & 0 \\
11 & No light, dark, 50 to $120{ }^{\circ} \mathrm{C}$ & 0
\end{tabular}

${ }^{a}$ Reaction conditions: pyridotriazole $\mathbf{1}(0.05 \mathrm{mmol})$, boronic acids 2 (1.5 equiv.), $\mathrm{K}_{2} \mathrm{CO}_{3}$ (3 equiv.), benzene ( $\left.0.1 \mathrm{M}\right)$, and a $40 \mathrm{~W} 390 \mathrm{~nm}$ LED at room temperature. ${ }^{b} \mathrm{GC} / \mathrm{MS}$ yields. thermal conditions in the absence of light (entry 11$).{ }^{11}$ Expectedly, the attempts on employment of pyridotriazoles $1 \mathrm{c}$ and $\mathbf{1 d}$, which are transparent in $390 \mathrm{~nm}$ region under these reaction conditions failed. Although the pyridotriazole 1d showed notable absorption in $370 \mathrm{~nm}$ region, the attempts of its arylation under irradiation with $370 \mathrm{~nm}$ LED lamp failed probably due to competing side reactions of the formed unstable carbene.

Intrigued by the uncovered novel reactivity of pyridotriazoles under photo-induced conditions and inspired by the importance of triarylmethanes, ${ }^{12}$ we further explored the scope of this arylation reaction. Markedly, this $\mathrm{C}-\mathrm{C}$ coupling reaction showed wide scope and high functional-group tolerance on both reaction partners (Table 2a). Thus, diversely functionalized boronic acids 2 bearing electron-rich (2b-2d), electron-

Table 2 Arylation reactions of pyridotriazoles ${ }^{a, b}$

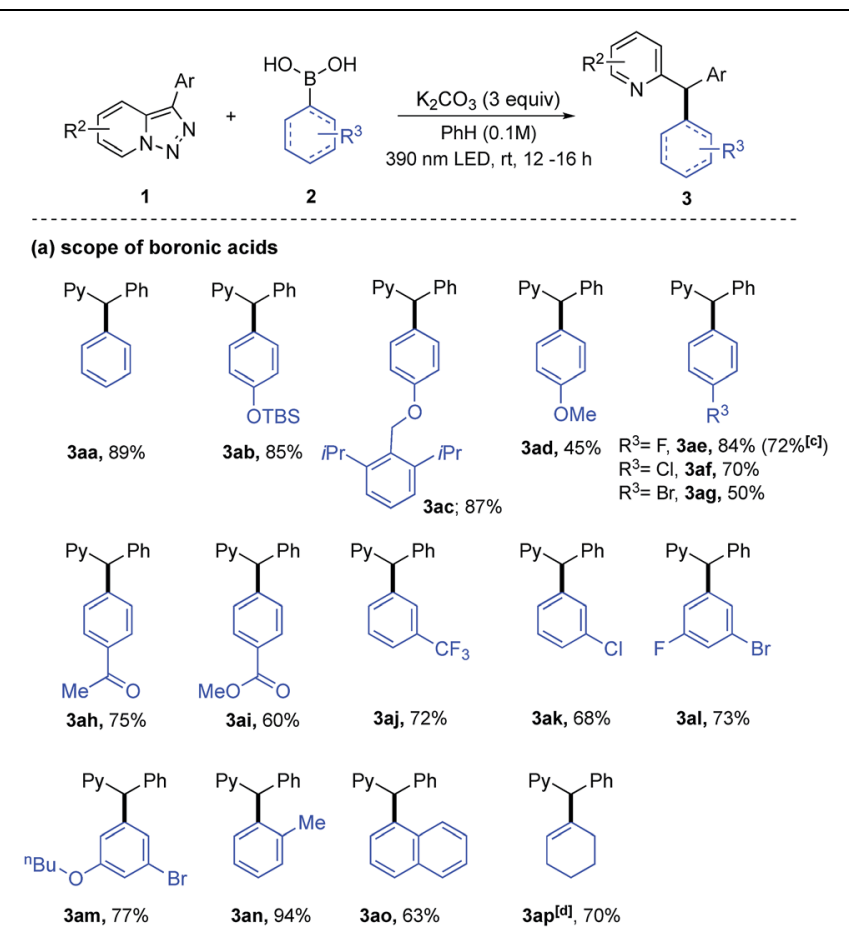

(b) scope of pyridotriazoles

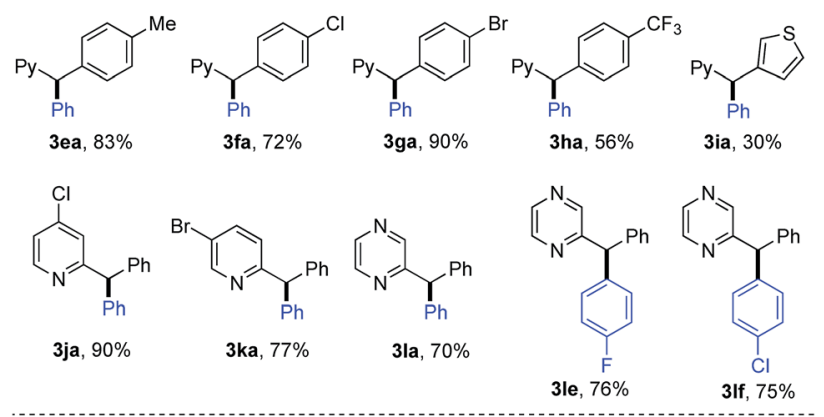

${ }^{a}$ Reaction conditions: pyridotriazole $1(0.2 \mathrm{mmol})$, boronic acids 2 (1.5 equiv.), $\mathrm{K}_{2} \mathrm{CO}_{3}$ (3 equiv.), benzene ( $\left.0.1 \mathrm{M}\right), 40 \mathrm{~W} 390 \mathrm{~nm} \mathrm{LED}$ at room temperature. ${ }^{b}$ Yield of isolated product. ${ }^{c}$ Reaction was performed in $1 \mathrm{mmol}$ scale. ${ }^{d}$ Toluene $(0.1 \mathrm{M})$ used as a solvent. 
deficient (2h-2j), electron-neutral (2n), halogen-containing (2e-2g and $2 \mathbf{k}-2 \mathbf{m})$, and sterically encumbered (2o) substituents at the ortho-, meta- and para-positions smoothly reacted with 3-phenyl[1,2,3]triazolo[1,5- $a]$ pyridine $\mathbf{1 a}$ to produce diphenyl-2-pyridylmethanes 3aa-3an in good to excellent yields. In addition, the reaction of phenylboronic acid with the para-siloxy substituent worked well to give $\mathbf{3 a b}$ in good yield, which upon desilylation offered access to the phenol product. Notably, the reaction also efficiently proceeded with the alkenyl boronic acid 2p providing cyclohexen-1-yl product 3ap in 70\% yield. Studies on the scope of pyridotriazoles showed that pyridotriazoles 1 bearing different 4-substituted phenyl or heteroaryl groups at C3 position furnished the corresponding triarylmethane products 3ea-3ia in moderate to high yields. In addition, 5-chloro pyridotriazole, 6-bromo pyridotriazole and $\mathrm{N}$-fused heterocyclic pyrazinotriazole successfully underwent arylation with different arylboronic acids to give $3 \mathbf{j a}, 3 \mathbf{k a}, 2-$ (diphenylmethyl) pyrazine (3la, 3le and 3lf) in good yields.

Next, we turned our attention to carbene $\mathrm{X}-\mathrm{H}$ insertion reactions $^{10 a}$ (Table 3). To this end, pyridotriazoles 1, under standard reaction conditions, were examined in reactions with phenols, alcohols, sulfonamides, and carboxylic acids (Table 3a). All substituted phenols tested provided the $\mathrm{O}-\mathrm{H}$ insertion products 7 aa-7af in moderate yields, albeit with trace to substantial amounts of the $\mathrm{C}-\mathrm{H}$ insertion regioisomers. ${ }^{13}$ These reaction conditions appeared to be very general for reactions with alcohols $\mathbf{4 g}-\mathbf{4 n}$. Thus, alcohols possessing various alkyl, alkenyl, thiomethyl, and even sterically hindered bicyclo groups all reacted well, providing ethers $7 \mathbf{a g}-\mathbf{7} \mathbf{f m}$ in good to high yields. Moreover, this reaction chemoselectively gave $\mathrm{O}-\mathrm{H}$ insertion products with alkenols (7al and 7am), double bond moiety of which was not compromised. Likewise, aliphatic chlorine substituent was tolerated in $\mathbf{4 n}$, which constitutes an additional handle for further derivatizations. In contrast to a facile $\mathrm{O}-\mathrm{H}$ insertion reaction with phenols, the insertion into the $\mathrm{N}-\mathrm{H}$ bond of aniline $\mathbf{5 a}$ was sluggish (Table $3 \mathrm{~b}$ ), which can probably be attributed to its higher $\mathrm{p} K_{\mathrm{a}}$ value. ${ }^{5 d}$ However, more acidic primary and secondary sulfonamides $\mathbf{5 b}-\mathbf{g}$ reacted smoothly to produce the $\mathrm{N}-\mathrm{H}$ insertions products $\mathbf{8 a b}-\mathbf{8 a g}$ in reasonable to high yields. Phthalimide $\mathbf{5 h}$ provided the insertion product $\mathbf{8 a h}$ in reasonable yield. Furthermore, both aliphatic and aromatic carboxylic acids 6a-6e were also found to be the competent substrates for the $\mathrm{COO}-\mathrm{H}$ insertion reactions producing the corresponding esters 9aa-9cc in good yields (Table 3c).

In addition, it was also found that upon photoirradiation, the pyridotriazoles underwent efficient cyclopropanation with alkenes 10 (Table 4). The scope of pyridotriazoles was studied first. Pyridotriazoles 1 bearing different 4-substituted phenyl or heteroaryl groups at $\mathrm{C} 3$ position gave the corresponding cyclopropanes 11aa-11ia in moderate to high yields. ${ }^{14}$ 3-Naphthalenyl pyridotriazole furnished product 11na in high yield. Furthermore, N-fused heterocyclic quinolinotriazole and 7chloro pyridotriazole successfully underwent cyclopropanation with styrene to give 11ma and 110a. The scope of the process with respect to the alkene components was examined next. Cyclopropanes 11ab-11ae were obtained from a diverse array of
Table $3 \quad \mathrm{X}-\mathrm{H}$ insertion reactions ${ }^{a b}$

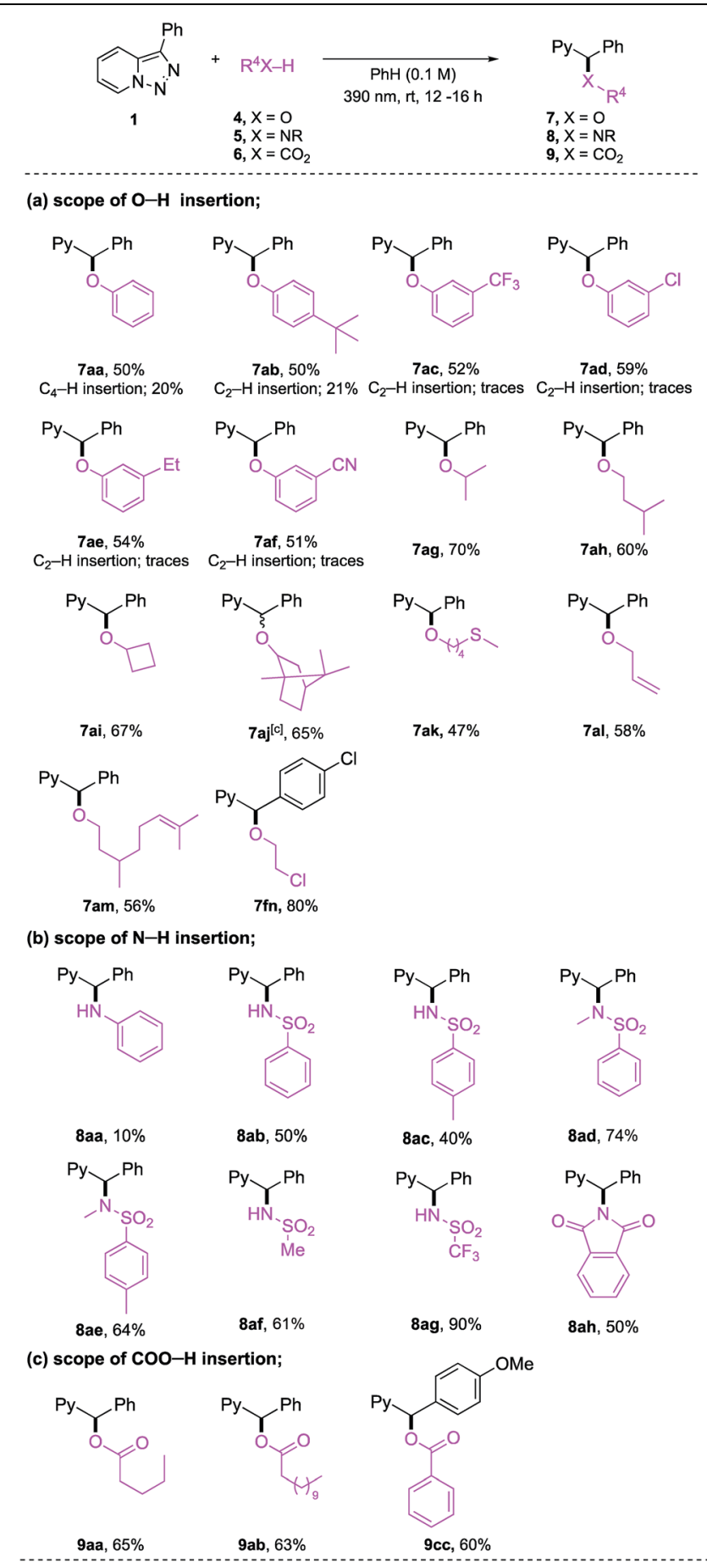

${ }^{a}$ Reaction conditions: pyridotriazole $\mathbf{1}(0.2 \mathrm{mmol}), \mathrm{X}-\mathrm{H}$ insertion partners 4, 5 or 6 (4 equiv.), benzene (0.1 M), $40 \mathrm{~W} 390 \mathrm{~nm}$ LED at room temperature. ${ }^{b}$ Yield of isolated product. ${ }^{c} \mathrm{dr} 1: 1$.

ortho-, meta-, para- and disubstituted styrenes in high yields. 2Vinylpyridine, vinyl ether, acrylonitrile, vinyl ketone and ethyl acrylate efficiently participated in the reaction to give the products 11ag-11ak. Notably, a double bond of indole also 
Table 4 Cyclopropanation reactions ${ }^{a}$

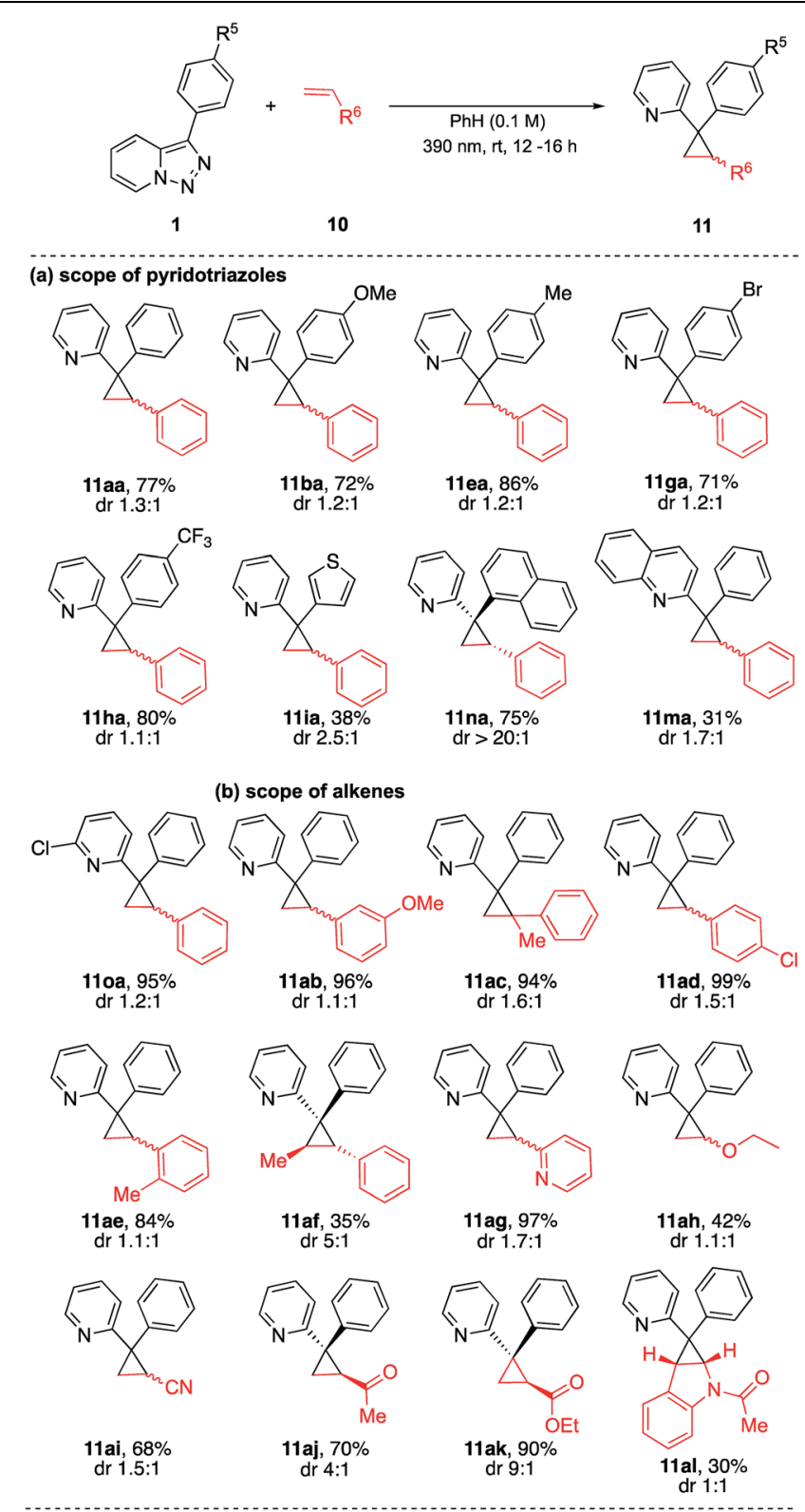
${ }^{a}$ Reaction conditions: pyridotriazole $\mathbf{1}(0.2 \mathrm{mmol})$, styrene 10 (3 equiv.),
benzene $(0.1 \mathrm{M}), 40 \mathrm{~W} 390 \mathrm{~nm}$ LED at room temperature.

participated in this reaction, providing fused product 11al in moderate yield.

Synthetic usefulness of this methodology was illustrated on the facile syntheses of selected bioactive molecules. Thus, desacetyl bisacodyl (DAB) $\mathbf{1 2}^{\mathbf{1 5}}$ and bisacodyl $13,{ }^{16}$ which are used as stimulant laxative drugs, were efficiently obtained via the one-pot procedures from the pyridotriazole 1b with arylboronic acid $\mathbf{2 b}$ (Scheme 2a). Furthermore, piperidine derivative $14,{ }^{17}$ the synthetic precursor of antihistamine agent Bepotastine, was easily accessed by the $\mathrm{O}-\mathrm{H}$ insertion reaction of $\mathbf{7 n}$ with pyridotriazole $\mathbf{1 f}$ (Scheme $2 \mathrm{~b}$ ). (a)

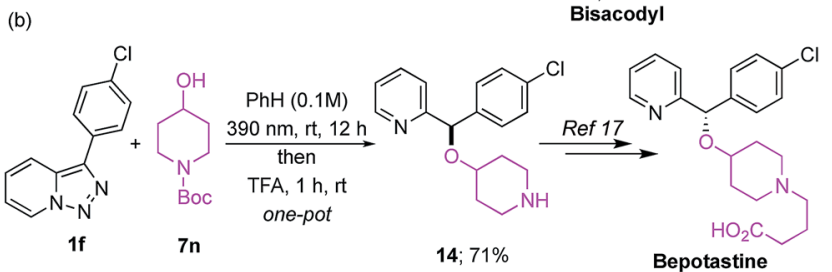

Scheme 2 Synthesis of biologically active molecules. (a) Conditions A: $\mathrm{HBr} / \mathrm{AcOH}=1: 1$, reflux, overnight. (b) Conditions $\mathrm{B}$ : $\mathrm{HBr} / \mathrm{AcOH}=$ $1: 1$, reflux, overnight. Then $\mathrm{Et}_{3} \mathrm{~N}$ (3 equiv.), $\mathrm{Ac}_{2} \mathrm{O}$ (4 equiv.), $\mathrm{DCM}(0.1$ M), rt, overnight.

\section{Conclusions}

We developed general and efficient arylation, $\mathrm{X}-\mathrm{H}$ insertions, and cyclopropanation reactions of pyridotriazoles. This transition metal-free light-induced ${ }^{18}$ protocol, operating under mild conditions, exhibits wide functional-group tolerance efficiently producing valuable triarylmethanes and heteroatomsubstituted benzylpyridine derivatives.

\section{Conflicts of interest}

There are no conflicts to declare.

\section{Acknowledgements}

We thank the National Institutes of Health (GM120281) and National Science Foundation (CHE-1663779) for the financial support of this work.

\section{Notes and references}

1 For reviews on reactivity of pyridotriazoles, see: (a) B. Chattopadhyay and V. Gevorgyan, Angew. Chem., Int. Ed., 2012, 51, 862-872; Angew. Chem., 2012, 124, 886-896; (b) P. Anbarasan, D. Yadagiri and S. Rajasekar, Synthesis, 2014, 46, 3004-3023.

2 For reviews on reactivity of $N$-sulfonyl triazoles, see: $(a)$ A. V. Gulevich and V. Gevorgyan, Angew. Chem., Int. Ed., 2013, 52, 1371-1373; Angew. Chem., 2013, 125, 1411-1413; (b) H. M. L. Davies and J. S. Alford, Chem. Soc. Rev., 2014, 43, 5151-5162; (c) Y. Jiang, R. Sun, X. Tang and M. Shi, Chem.-Eur. J., 2016, 22, 17910-17924. 
3 For the first report on transannulation of pyridotriazoles, see: (a) S. Chuprakov, F. Hwang and V. Gevorgyan, Angew. Chem., Int. Ed., 2007, 46, 4757-4759; Angew. Chem., 2007, 119, 4841-4843; see also: (b) S. Chuprakov and V. Gevorgyan, Org. Lett., 2007, 9, 4463-4466; (c) Y. Shi, A. V. Gulevich and V. Gevorgyan, Angew. Chem., Int. Ed., 2014, 53, 14191-14195; (d) V. Helan, A. V. Gulevich and V. Gevorgyan, Chem. Sci., 2015, 6, 1928-1931; (e) Y. Shi and V. Gevorgyan, Chem. Commun., 2015, 51, 17166-17169; $(f)$ J. H. Kim, T. Gensch, D. Zhao, L. Stegemann, C. A. Strassert and F. Glorius, Angew. Chem., Int. Ed., 2015, 54, 10975-10979; $(g)$ W. H. Jeon, J. Y. Son, J. E. Kim and P. H. Lee, Org. Lett., 2016, 18, 3498-3501; (h) A. Joshi, D. C. Mohan and S. Adimurthy, J. Org. Chem., 2016, 81, 9461-9469; (i) A. Joshi, D. C. Mohan and S. Adimurthy, Org. Lett., 2016, 18, 464-467; (j) R. Adam, S. Alom, B. Abarca and R. Ballesteros, Tetrahedron, 2016, 72, 84368441; (k) H. Kim, S. Kim, J. Kim, J.-Y. Son, K. Um and P. H. Lee, Org. Lett., 2017, 19, 5677-5680; (l) S. Roy, S. K. Das and B. Chattopadhyay, Angew. Chem., Int. Ed., 2018, 57, 2238-2243.

4 For selected reports on transannulation of $N$-sulfonyl triazoles, see: (a) T. Horneff, S. Chuprakov, N. Chernyak, V. Gevorgyan and V. V. Fokin, J. Am. Chem. Soc., 2008, 130, 14972-14974; (b) T. Miura, M. Yamauchi and M. Murakami, Chem. Commun., 2009, 1470-1471; (c) B. Chattopadhyay and V. Gevorgyan, Org. Lett., 2011, 13, 3746-3749; (d) B. T. Parr, S. A. Green and H. M. L. Davies, J. Am. Chem. Soc., 2013, 135, 4716-4718; (e) J. E. Spangler and H. M. L. Davies, J. Am. Chem. Soc., 2013, 135, 68026805; (f) J. S. Alford, J. E. Spangler and H. M. L. Davies, J. Am. Chem. Soc., 2013, 135, 11712-11715; $(g)$ B. T. Parr and H. M. L. Davies, Angew. Chem., Int. Ed., 2013, 52, 1004410047; Angew. Chem., 2013, 125, 10228-10231; (h) M. Zibinsky and V. V. Fokin, Angew. Chem., Int. Ed., 2013, 52, 1507-1510; Angew. Chem., 2013, 125, 1547-1550; (i) S. Chuprakov, S. W. Kwok and V. V. Fokin, J. Am. Chem. Soc., 2013, 135, 4652-4655; (j) T. Miura, T. Tanaka, K. Hiraga, S. G. Stewart and M. Murakami, J. Am. Chem. Soc., 2013, 135, 13652-13655; (k) T. Miura, K. Hiraga, T. Biyajima, T. Nakamuro and M. Murakami, Org. Lett., 2013, 15, 3298-3301; (l) E. E. Schultz and R. Sarpong, J. Am. Chem. Soc., 2013, 135, 4696-4699; $(m)$ Y. Shi and V. Gevorgyan, Org. Lett., 2013, 15, 5394-5396; (n) T. Miura, Y. Funakoshi and M. Murakami, J. Am. Chem. Soc., 2014, 136, 2272-2275; (o) C. Kim, S. Park, D. Eom, B. Seo and P. H. Lee, Org. Lett., 2014, 16, 1900-1903; (p) J. Yang, C. Zhu, X. Tang and M. Shi, Angew. Chem., Int. Ed., 2014, 53, 5142-5146; Angew. Chem., 2014, 126, 5242-5246; (q) H. Shang, Y. Wang, Y. Tian, J. Feng and Y. Tang, Angew. Chem., Int. Ed., 2014, 53, 5662-5666; (r) K. Chen, Z.-Z. Zhu, Y.-S. Zhang, X.-Y. Tang and M. Shi, Angew. Chem., Int. Ed., 2014, 53, 6645-6649; $(s)$ F. Medina, C. Besnard and J. Lacour, Org. Lett., 2014, 16, 3232-3235; $(t)$ V. N. G. Lindsay, H. M.-F. Viart and R. Sarpong, J. Am. Chem. Soc., 2015, 137, 8368-8371; (u) W. Cheng, Y. Tang, Z. $\mathrm{Xu}$ and C. Li, Org. Lett., 2016, 18, 6168-6171; (v) Y. Li,
R. Zhang, A. Ali, J. Zhang, X. Bi and J. Fu, Org. Lett., 2017, 19, 3087-3090; (w) L. Fu, H. M. L. Davis and R. Sarpong, Org. Lett., 2017, 19, 1504-1507; (x) W. Chen, Y. Bai, Y. Luo and P. Xu, Org. Lett., 2017, 19, 364-367; (y) D. Yadagiri, M. Chaitanya, A. C. S. Reddy and P. Anbarasan, Org. Lett., 2018, 20, 3762-3765.

5 For selected reports on $\mathrm{X}-\mathrm{H}$ insertions of $\mathrm{N}$-sulfonyl triazoles, see: (a) S. Chuprakov, J. A. Malik, M. Zibinsky and V. V. Fokin, J. Am. Chem. Soc., 2011, 133, 10352-10355; (b) T. Miura, T. Biyajima, T. Fujii and M. Murakami, J. Am. Chem. Soc., 2012, 134, 194-196; (c) T. Miura, T. Tanaka, T. Biyajima, A. Yada and M. Murakami, Angew. Chem., Int. Ed., 2013, 52, 3883-3886; Angew. Chem., 2013, 125, 39753978; (d) S. Chuprakov, B. T. Worrell, N. Selander, R. K. Sit and V. V. Fokin, J. Am. Chem. Soc., 2014, 136, 195-202; (e) T. Miura, Q. Zhao and M. Murakami, Angew. Chem., Int. Ed., 2017, 56, 16645-16649.

6 For selected reports on cyclopropanation of $\mathrm{N}$-sulfonyl triazoles, see: (a) S. Chuprakov, S. W. Kwok, L. Zhang, L. Lercher and V. V. Fokin, J. Am. Chem. Soc., 2009, 131, 18034-18035; (b) N. Grimster, L. Zhang and V. V. Fokin, J. Am. Chem. Soc., 2010, 132, 2510-2511; (c) J. S. Alford and H. M. L. Davies, Org. Lett., 2012, 14, 6020-6023; (d) J. C. Culhane and V. V. Fokin, Org. Lett., 2011, 13, 4578-4580.

7 For selected transformations on $N$-sulfonyl triazoles, see: $(a)$ N. Selander, B. T. Worrell, S. Chuprakov, S. Velaparthi and V. V. Fokin, J. Am. Chem. Soc., 2012, 134, 14670-14673; (b) D. Yadagiri, A. C. S. Reddy and P. Anbarasan, Chem. Sci., 2016, 7, 5934-5938; (c) A. Bosmani, A. Guarnieri-Ibáñez, S. Goudedranche, C. Besnard and J. Lacour, Angew. Chem., Int. Ed., 2018, 57, 7151-7155.

8 M. Ratushnyy, M. Kamenova and V. Gevorgyan, Chem. Sci., 2018, 9, 7193-7197.

9 Harsh UVC irradiation by $\mathrm{Hg}$-Xe lamp combined with monochromators or fillers was $\operatorname{reported}(a)$ M. Kuzaj, H. Lüerssen and C. Wentrup, Angew. Chem., Int. Ed., 1986, 25, 480-482; (b) K. Komatsu, N. Ichikawa and H. Tomioka, J. Am. Chem. Soc., 1993, 115, 8621-8626; (c) A. Ignatchenko and H. E. Zimmerman, J. Org. Chem., 1999, 64, 6635-6645; (d) A. Kuhn, C. Plüg and C. Wentrup, J. Am. Chem. Soc., 2000, 122, 1945-1948; (e) C. Plüg, A. Kuhn and C. Wentrup, J. Chem. Soc., Perkin Trans. 1, 2002, 1366-1368; (f) H. G. Aderson, P. Bednarek and C. Wentrup, J. Phys. Org. Chem., 2003, 16, 519-524; (g) N. Fu, A. D. Allen, S. Kobayashi, P. A. Sequeira, M. Shang, T. T. Tidewell and M. Mishima, J. Am. Chem. Soc., 2007, 129, 6210-6215. For recent report on photo-redox transformation of benzotriazoles, see: (h) M. Teders, A. Gómez-Suárez, L. Pitzer, M. N. Hopkinson and F. Glorius, Angew. Chem., Int. Ed., 2017, 56, 902-906; (i) M. Teders, L. Pitzer, S. Buss and F. Glorius, ACS Catal., 2017, 7, 4053-4056.

10 (a) I. D. Jurberg and H. M. L. Davies, Chem. Sci., 2018, 9, 5112-5118; (b) T. Xiao, M. Mei, Y. He and L. Zhou, Chem. Commun., 2018, 54, 8865-8868; (c) R. Hommelsheim, Y. Guo, Z. Yang, C. Empel and R. M. Koenigs, Angew. Chem., Int. Ed., 2019, 58, 1203-1207; (d) Ł. W. Ciszewski, K. Rybicka-Jasińska and D. Gryko, Org. Biomol. Chem., 
2019, 17, 432-448; (e) F. He and R. M. Koenigs, Chem. Commun., 2019, 55, 4881-4884; (f) J. Yang, J. Wang, H. Huang, G. Qin, Y. Jiang and T. Xiao, Org. Lett., 2019, 21, 2654-2657; (g) S. Jana and R. M. Koenigs, Asian J. Org. Chem., 2019, 8, 683-686; (h) Z. Yang, Y. Guo and R. M. Koenigs, Chem.-Eur. J., 2019, 25, 6703; (i) X. Zhang, C. Du, H. Zhang, X. Li, Y. Wang, J. Niu and M. Song, Synthesis, 2019, 51, 889-898.

11 During manuscript preparation, a related work on thermal arylation of mostly activated pyridotriazoles has been reported, see: C. Dong, X. Wang, Z. Pei and R. Shen, Org. Lett., 2019, 21, 4148-4152.

12 For application and importance of triarylmethanes, see: $(a)$ M. Irie, J. Am. Chem. Soc., 1983, 105, 2078-2079; (b) D. Duxbury, Chem. Rev., 1993, 93, 381-433; (c) M. S. Shchepinov, Chem. Soc. Rev., 2003, 32, 170-180; (d) R. S. Dothager, K. S. Putt, B. J. Allen, B. J. Leslie, V. Nesterenko and P. J. Hergenrother, J. Am. Chem. Soc., 2005, 127, 8686-8696; (e) V. Nair, S. Thomas, S. C. Mathew and K. G. Abhilash, Tetrahedron, 2006, 62, 6731-6747; $(f)$ A. C. Bhasikuttan, J. Mohanty, W. M. Nau and H. Pal, Angew. Chem., Int. Ed., 2007, 46, 4120-4122; (g) S. K. Das, G. Panda, V. Chaturvedi, Y. S. Manju, A. K. Gaikwad and S. Sinha, Bioorg. Med. Chem. Lett., 2007, 17, 5586-5589; (h) H. Abe, J. Wang, K. Furukawa, K. Oki, M. Uda, S. Tsuneda and Y. Ito, Bioconjugate Chem., 2008, 19, 1219-1226; (i) H. N. Kim, M. H. Lee, H. J. Kim, J. S. Kim and J. Yoon, Chem. Soc. Rev., 2008, 37, 1465-1472; (j) M. Beija, C. A. M. Afonso and M. G. Martinho, Chem. Soc. Rev., 2009, 38, 2410-2433. For the synthesis of triarylmethanes, selected examples: (k) T. Niwa, H. Yorimitsu and K. Oshima, Org. Lett., 2007, 9, 2373-2375; (l) Y. Xia, F. Hu, Z. Liu, P. Qu, R. Ge, C. Ma, Y. Zhang and J. Wang, Org. Lett., 2013, 15, 1784-1787; $(m)$ M. Nambo and C. M. Crudden, Angew. Chem., Int. Ed., 2014, 53, 742-746; (n) X. Cao, S. Sha, B. Kim, C. Morgan, R. Huang, C. Yang and P. J. Walsh, Chem. Sci., 2016, 7, 611-618.

13 For nucleophilic addition of electron-rich arenes to rhodium carbenoids, see: (a) D. Yadagiri and P. Anbarasan, Org. Lett., 2014, 16, 2510-2513; (b) S. Shin, Y. Park, C. Kim, J. Son and P. Lee, J. Org. Chem., 2015, 80, 5859-5869. We were unsuccessful under optimized condtion with different electron rich arenes using stoichiometric amount of solvent. 14 Employment of methyl-substituted pyridotriazole 1d under $370 \mathrm{~nm}$ irradiation produced trace amounts of the product. 15 T. Fujita, S. Karaki, T. Tateika and A. Kuwahara, Biomed. Res., 2016, 37, 13-20.

16 (a) R. D. Kacere, S. S. Srivatsa, W. J. Tremaine, L. E. Ebnet and K. P. Batts, Mayo Clin. Proc., 1993, 68, 355-357; (b) K. Kudo, C. Miyazaki, R. Kadoya, T. Imamura, N. Jitsufuchi and N. Ikeda, J. Anal. Toxicol., 1998, 22, 274-278; (c) S. D. Wexner, T. Force, D. E. Beck, T. H. Baron, R. D. Fanelli, N. Hyman, B. Shen and K. E. Wasco, Gastrointestinal Endoscopy, 2006, 63, 894-909.

17 T. H. Ha, K. H. Suh and G. S. Lee, Bull. Korean Chem. Soc., 2013, 34, 549-553.

18 Test experiments indicated that analogously to the arylation reaction (Table 1, entry 11), no $\mathrm{X}-\mathrm{H}$ insertion or cyclopropanation reactions occur under dark conditions. 